\title{
Body mass index and the risk of meningioma, glioma and schwannoma in a large prospective cohort study (The HUNT Study)
}

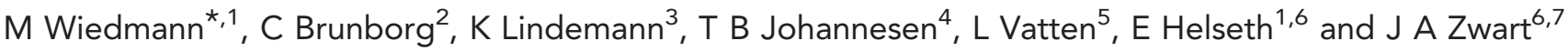 \\ ${ }^{1}$ Department of Neurosurgery, Oslo University Hospital, 0407 Oslo, Norway; ${ }^{2}$ Unit of Biostatistics and Epidemiology, Oslo \\ University Hospital, 0407 Oslo, Norway; ${ }^{3}$ Department of Obstetrics and Gynaecology, Akershus University Hospital, 1478 \\ Lørenskog, Norway; ${ }^{4}$ The Cancer Registry of Norway, 0369 Oslo, Norway; ${ }^{5}$ Department of Public Health, Norwegian University of \\ Science and Technology, 7491 Trondheim, Norway; ${ }^{6}$ Faculty of Medicine, University of Oslo, 0316 Oslo, Norway and ${ }^{7}$ FORMI and \\ Department of Neurology, Oslo University Hospital, 0407 Oslo, Norway
}

Background: Obesity increases the risk for a number of solid malignant tumours. However, it is not clear whether body mass index (BMI) and height are associated with the risk of primary tumours of the central nervous system (CNS).

Methods: In a large population study (The Nord-Trøndelag Health Study (HUNT Study)) of 74242 participants in Norway, weight and height were measured. During follow-up, incident CNS tumours were identified by individual linkage to the Norwegian Cancer Registry. Sex- and age-adjusted and multivariable Cox regression analyses were used to evaluate BMl and height in relation to the risk of meningioma, glioma and schwannoma.

Results: A total of 138 meningiomas, 148 gliomas and 39 schwannomas occurred during 23.5 years (median, range 0-25) of followup. In obese women (BMI $\geqslant 30 \mathrm{~kg} \mathrm{~m}^{-2}$ ), meningioma risk was $67 \%$ higher (hazard ratio $(\mathrm{HR})=1.68,95 \%$ confidence interval $(\mathrm{Cl})$ : 0.97-2.92, $P$-trend $=0.05$ ) than in the reference group (BMI 20-24.9 $\mathrm{kg} \mathrm{m}^{-2}$ ), whereas no association with obesity was observed in males. There was no association of BMI with glioma risk, but there was a negative association of overweight/obesity (BMI $\geqslant 25 \mathrm{~kg} \mathrm{~m}^{-2}$ ) with the risk of schwannoma ( $\mathrm{HR}=0.48,95 \% \mathrm{Cl}$ : 0.23-0.99). However, the schwannoma analysis was based on small numbers. Height was not associated with the risk for any tumour subgroup.

Conclusion: These results suggest that BMI is positively associated with meningioma risk in women, and possibly, inversely associated with schwannoma risk.

Primary central nervous system (CNS) tumours are a heterogeneous group of benign and malignant neoplasms arising from different cell types. Among adults, these tumours account for 3.0$3.5 \%$ of all cancers (CBTRUS, 2012). The overall annual incidence of primary CNS tumours is about 20 per 100000 person-years (CBTRUS, 2012; Kreftregisteret, 2011). The four most common primary CNS tumours in adults include meningiomas $(34.7 \%)$, gliomas (30\%), pituitary adenomas (13.5\%) and nerve sheath tumours (8.5\%) (CBTRUS, 2012). Gliomas are intrinsic CNS tumours derived from glial cells. Highly malignant glioblastomas are the most common type, with a median survival of about 10 months (Ronning et al, 2012). Meningiomas are extrinsic and most often benign CNS tumours arising from the meningothelial cells of the arachnoid. Schwannomas are the most common nerve sheath tumours and arise from the Schwann cells, which myelinate peripheral nerves. For the majority of meningiomas and schwannomas radical surgery is curative.

The risk of CNS neoplasms increases with age and a minority of tumours is associated with rare genetic syndromes (Bondy et al, 1994; Inskip et al, 1995; Preston-Martin, 1996; Fisher et al, 2007). 
Meningiomas are more than twice as common in women than men, whereas gliomas are more common in men. Caucasians have a higher incidence of gliomas compared to African-Americans, but the incidence of meningiomas is higher in African-Americans than in Caucasians (Chakrabarti et al, 2005; Ries et al, 2011; CBTRUS, 2012). The only known modifiable risk factor for meningiomas, gliomas and schwannomas is exposure to ionising radiation (Inskip et al, 1995; Umansky et al, 2008).

High body mass index (BMI) is a major risk factor for a number of diseases, including cancer of the endometrium, colon, breast (postmenopausal) and kidney (Renehan et al, 2008). In relation to brain tumours, results of anthropometric factors have been inconsistent (Tulinius et al, 1997; Calle et al, 2003; Oh et al, 2005; Parr et al, 2010; Edlinger et al, 2012). Whereas several recent prospective cohort studies suggested a positive association of BMI with meningioma risk (Jhawar et al, 2003; Benson et al, 2008; Johnson et al, 2011; Michaud et al, 2011), another did not support this association (Helseth and Tretli, 1989). Height was positively associated with glioma risk in two recent prospective cohort studies (Benson et al, 2008; Moore et al, 2009), but the association was not confirmed in another study (Michaud et al, 2011). In one cohort study, obesity at the age of 18 years was positively associated with glioma risk later in life (Moore et al, 2009).

On this background, we used data from a large populationbased cohort to examine the association of BMI and height with the risk of meningioma, glioma and schwannoma.

\section{MATERIALS AND METHODS}

During 1984-1986, a general health survey was conducted among men and women aged $\geqslant 20$ years in Nord-Trøndelag County (HUNT 1) in Norway. Among 85100 eligible persons, 77310 $(90.8 \%)$ returned the questionnaire that was mailed with the invitation (questionnaire 1). A total of 74977 (88.1\%) participants attended the subsequent physical examination that included standardised measurements of height and weight. At the examination, participants received a second questionnaire, including items on life-style factors and medical history, which was to be filled in at home and returned in a prestamped envelope. The HUNT study is described in detail elsewhere (Holmen et al, 1991) and details of the questionnaires can be found on the HUNT study's website (www.ntnu.edu/hunt).

Information on BMI was available in 74339 (87.4\%) participants. Among these, 72 were excluded because of prevalent primary CNS tumours and 25 because of missing follow-up data. Thus, $74242(87.4 \%)$ individuals constituted the study population and were followed-up for primary CNS tumour incidence from the baseline measurements until the end of follow-up, 31 December, 2008.

Every Norwegian citizen has a unique 11-digit ID number, which enabled individual linkage to incidence data at the Cancer Registry of Norway. The topography codes (International Classification of Diseases, 7th Revision, ICD-7) that were used included C70 (meninges), C71 (brain), C72 (spinal cord, cranial nerves and other parts of the CNS). The information on CNS tumours in the Norwegian Cancer Registry is based on mandatory reporting from clinicians and pathology departments, as well as death certificates, hospital discharge data and radiotherapy data. We defined subgroups of CNS neoplasms using ICD-O-3 histology codes (International Classification of Diseases for Oncology, Third Edition) 9380-9480 for gliomas, 9530-9539 for meningiomas and 9560 for schwannomas.

Standardised measurements of height (in $\mathrm{cm}$ ) and weight (in $\mathrm{kg}$ ) were performed at the baseline clinical examination, and BMI was calculated as weight divided by height squared $\left(\mathrm{kg} \mathrm{m}^{-2}\right)$ and categorised as $<20,20-24.9,25-29.9$ and $\geqslant 30 \mathrm{~kg} \mathrm{~m}^{-2}$. Physical activity (that is, walking, skiing, swimming or other sports) was assessed as frequency of the activity per week. Age was categorised as $20-29,30-39,40-49,50-59,60-69$ and $>70$ years. Marital status was divided into four categories: married, unmarried, widowed or divorced/separated. Level of education was categorised into three levels according to duration: $<10,10-12$ or $>12$ years of school. Further, participants were categorised into three levels of smoking (never, former or current) and into five categories of alcohol drinking $(0,1-4,5-10,>10$ times during the last 2 weeks or 'total abstainer').

The Regional Committee for Ethics in Medical Research and the Norwegian Data Inspectorate approved this study.

Statistical analysis. Follow-up time was calculated as person-years from the date of clinical examination until the date of primary CNS tumour diagnosis (meningioma, glioma or schwannoma), emigration, death from any cause or until the end of follow-up at 31 December 2008, whichever occurred first. Patients with CNS tumours other than the ones that were considered as end points in the analysis were excluded.

Cox proportional hazard regression was used to calculate age- and sex-adjusted and multivariable hazard ratios (HRs) with 95\% confidence intervals (CIs). Covariates, identified as independent risk factors of CNS tumours in previous studies, were included in the model whenever available in the data. Further, covariates were included that could potentially influence BMI, including smoking, alcohol use, physical activity and socio-economic status. Several models were fitted, ranging from simple age- and sex-controlled models to multivariable models. Interactions were evaluated by including appropriate product terms in the model. Covariates that did not substantially change the estimated HRs were excluded from the final model.

Linear trends were tested using categories of BMI as described above and per $10 \mathrm{~cm}$ increase in height. In the trend analyses, these factors were treated as ordinal scores.

The proportional hazard assumptions were tested by plotting the logarithm of the integrated hazards (log-log survival plots) and by Schoenfeld tests, and found to be satisfied. STATA statistics software Version 12.1 (StataCorp, College Station, TX 77845, USA) was used for statistical analysis.

\section{RESULTS}

During 23.5 years (median, range 0-25) of follow-up of 74242 individuals, 148 incident gliomas, 138 meningiomas and 39 schwannomas were identified. Baseline characteristics of the study population are described in Table 1. Diagnosis was based on histology in 140 (95\%) gliomas, 81 (59\%) meningiomas and 18 (46\%) schwannomas, and the remaining tumours were diagnosed based on radiology. Tumours incidentally found at autopsy were excluded from the study.

Age- and sex-adjusted HRs for each specific tumour type by BMI and height are shown in Table 2. Multivariable analysis, also including level of education, marital status, usual physical activity level, smoking status and usual alcohol consumption did not substantially influence the associations for meningiomas and gliomas, and the multivariable estimates for these tumour subgroups are not presented. Smoking status was significantly associated with schwannoma risk and was included in the final model for this tumour subgroup. Further, we tested for interaction between BMI and sex in relation to meningioma risk, and confirmed a significant interaction $(P<0.02)$. Therefore, sexspecific analyses were conducted for the meningioma subgroup.

Thus, there was a positive association per BMI category among women and the risk of meningioma (HR 1.27, 95\% CI: 1.00-1.62; 
Table 1. Baseline characteristics of the HUNT 1 Study population according to the population at risk and the tumour incidence

\begin{tabular}{|c|c|c|c|c|c|c|c|c|}
\hline \multirow[b]{2}{*}{ Characteristic } & \multicolumn{2}{|c|}{ Population at risk } & \multicolumn{2}{|c|}{ Meningioma } & \multicolumn{2}{|c|}{ Glioma } & \multicolumn{2}{|c|}{ Schwannoma } \\
\hline & Female & Male & Female & Male & Female & Male & Female & Male \\
\hline Number of subjects & 37765 & 36477 & 108 & 30 & 65 & 83 & 20 & 19 \\
\hline Median age at entry ${ }^{a}$ & $48.1(20-101)$ & $46.8(20-100)$ & $49.8(26-78)$ & $47.2(21-71)$ & $43.9(21-67)$ & $47.4(22-77)$ & $40(28-71)$ & $40(25-62)$ \\
\hline Median height ${ }^{\mathrm{a}}, \mathrm{cm}$ & $163(120-194)$ & $176(133-207)$ & 162 (143-179) & 175 (164-184) & 165 (154-185) & $178(165-194)$ & 165 (150-172) & 178 (172-188) \\
\hline Median weight ${ }^{\mathrm{a}}, \mathrm{kg}$ & $65(35-150)$ & $77.5(35-155)$ & 65 (49-102) & 79 (64-100) & 64.5 (49-113) & $79(55-112)$ & $64.5(51-80)$ & $78.5(68-101)$ \\
\hline $\begin{array}{l}\text { Median BMI', } \\
\mathrm{kg} \mathrm{m}^{-2}\end{array}$ & $24.3(14-55)$ & $24.9(14-45)$ & $25.5(18-39)$ & 25 (22.4-33) & $23.4(19-44)$ & $24.9(19-34)$ & $23.8(20-31)$ & $23.9(20-28)$ \\
\hline Married (\%) & 69 & 70 & 66 & 82 & 79 & 80 & 90 & 84 \\
\hline $\begin{array}{l}\text { Education }>12 \\
\text { years }(\%)\end{array}$ & 7 & 9 & 6 & 17 & 8 & 10 & 10 & 26 \\
\hline $\begin{array}{l}\text { Physical activity } \\
\text { 'every day' (\%) }\end{array}$ & 11 & 11 & 5 & 12 & 7 & 23 & 5 & 11 \\
\hline $\begin{array}{l}\text { Alcohol } \geqslant 5 \text { times } \\
\text { per } 2 \text { weeks (\%) }\end{array}$ & 3 & 7 & 3 & 12 & 3 & 3 & 0 & 5 \\
\hline Current smoker (\%) & 25 & 30 & 35 & 29 & 25 & 23 & 15 & 11 \\
\hline
\end{tabular}

Table 2. HRs $(95 \% \mathrm{Cls})$ for $\mathrm{BMI}$ and height and the risk of meningioma, glioma and schwannoma in the HUNT 1 Study

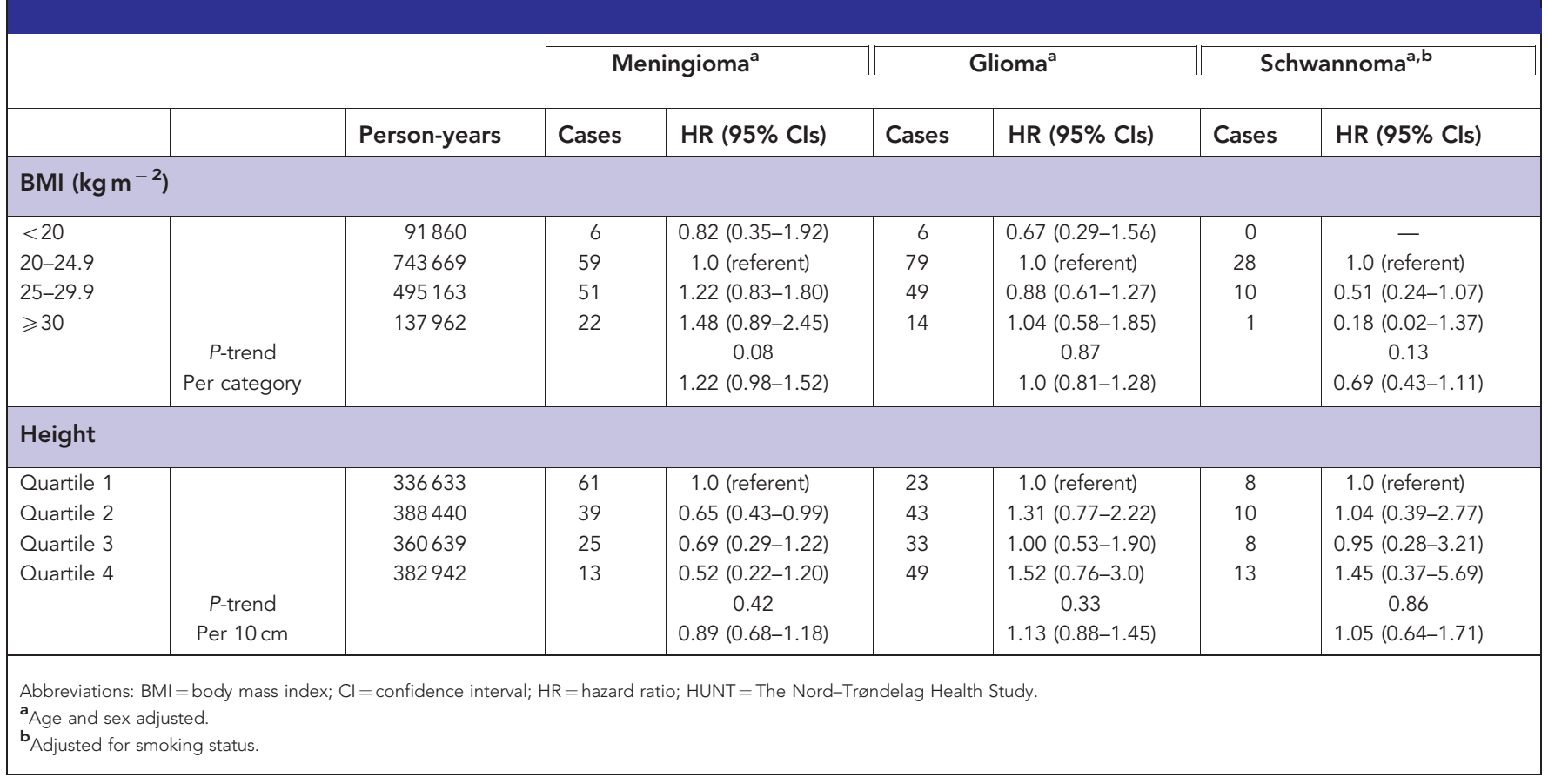

$P$-trend $=0.05)$ (Table 3$)$. The HR for obese women $(\mathrm{BMI} \geqslant 30)$ compared with the reference group (BMI 20-24.9) was 1.68 (95\% CI: 0.97-2.92). For height, there was a weak inverse association that was not statistically significant (Table 3). Among men, neither BMI nor height was associated with the risk of meningioma (Table 3).

For glioma risk, there was no evidence for any association with BMI or height in our data.

In the analysis of schwannoma risk, there was a not significant negative association of BMI (HR 0.69, 95\% CI: 0.43-1.11; $P$-trend $=0.13$ ), but no association of height (Table 2).

In a separate exploratory analysis, we dichotomised BMI to increase statistical power. We found that overweight/obesity (BMI $\geqslant 25$ ) was associated with about half the risk of schwannoma compared to having a BMI <25 (HR 0.48, 95\% CI: 0.23-0.99) (Table 4).

Changes in BMI may be due to a preclinical effect of malignant disease. To control for this possible bias, a follow-up time $\leqslant 5$ years was excluded from the analysis, affecting 4 schwannoma and 12 meningioma cases. However, the estimated effects related to schwannoma in both genders (5 years follow-up excluded: HR 0.46, 95\% CI: 0.22-0.99 compared with HR 0.47, 95\% CI: $0.23-0.97$ ) and meningioma in females (5 years follow-up excluded: HR 1.30, 95\% CI: 1.00-1.69 compared with HR 1.27, 95\% CI: 1.00-1.62) remained stable.

In a sensitivity analysis restricted to schwannomas in both genders and meningiomas in women diagnosed by morphology 
Table 3. HRs ( $95 \% \mathrm{Cls}$ ) of meningioma in relation to $\mathrm{BMI}$ and height (sex-specific analysis)

\begin{tabular}{|c|c|c|c|c|c|}
\hline & & \multicolumn{2}{|c|}{ Women ${ }^{a}$} & \multicolumn{2}{|c|}{ Men $^{a}$} \\
\hline & & Cases & HR (95\% Cls) & Cases & HR $(95 \% \mathrm{Cls})$ \\
\hline \multicolumn{6}{|c|}{ BMI $\left(\mathrm{kg} \mathrm{m}^{-2}\right)$} \\
\hline $\begin{array}{l}<20 \\
20-24.9 \\
25-29.9 \\
\geqslant 30\end{array}$ & $\begin{array}{c}\text { P-trend } \\
\text { Per category }\end{array}$ & $\begin{array}{r}6 \\
44 \\
38 \\
20\end{array}$ & $\begin{array}{c}0.95 \text { (0.40-2.25) } \\
1.0 \text { (referent) } \\
1.37 \text { (0.87-2.14) } \\
1.68(0.97-2.92) \\
0.05 \\
1.27(1.00-1.62)\end{array}$ & $\begin{array}{r}0 \\
15 \\
13 \\
2\end{array}$ & $\begin{array}{c}- \\
1.0 \text { (referent) } \\
0.88 \text { (0.41-1.86) } \\
0.76(0.17-3.37) \\
0.91 \\
0.97(0.56-1.67)\end{array}$ \\
\hline \multicolumn{6}{|l|}{ Height } \\
\hline $\begin{array}{l}\text { Quartile } 1 \\
\text { Quartile } 2 \\
\text { Quartile } 3 \\
\text { Quartile } 4\end{array}$ & $\begin{array}{l}\text { P-trend } \\
\text { Per } 10 \mathrm{~cm}\end{array}$ & $\begin{array}{l}33 \\
32 \\
25 \\
18\end{array}$ & $\begin{array}{c}1.0 \text { (referent) } \\
1.00(0.61-1.65) \\
0.82(0.48-1.41) \\
0.63(0.34-1.15) \\
0.15 \\
0.79(0.57-1.09)\end{array}$ & $\begin{array}{r}7 \\
12 \\
5 \\
6\end{array}$ & $\begin{array}{c}1.0 \text { (referent) } \\
2.01 \text { (0.78-5.16) } \\
0.77(0.24-2.49) \\
1.20(0.38-3.77) \\
0.40 \\
1.26(0.74-2.15)\end{array}$ \\
\hline
\end{tabular}

Table 4. $\mathrm{HRs}^{\mathrm{a}}$ (95\% Cls) of schwannoma in relation to $\mathrm{BMI}$ and height (pooled analysis)

\begin{tabular}{|c|c|c|c|}
\hline & & Cases & HR (95\% Cls) \\
\hline \multicolumn{4}{|l|}{ BMI $\left(\mathrm{kg} \mathrm{m}^{-2}\right)$} \\
\hline $\begin{array}{l}<25 \\
\geqslant 25\end{array}$ & $P$ & $\begin{array}{l}28 \\
11\end{array}$ & $\begin{array}{c}1.0 \\
0.47(0.23-0.97) \\
0.04\end{array}$ \\
\hline \multicolumn{4}{|l|}{ Height } \\
\hline $\begin{array}{l}\text { Quartile } 1+2 \\
\text { Quartile } 3+4\end{array}$ & $P$ & $\begin{array}{l}18 \\
21\end{array}$ & $\begin{array}{c}1.0 \\
1.04(0.41-2.66) \\
0.93\end{array}$ \\
\hline
\end{tabular}

only, the point estimates of the associations of BMI were nearly identical to the results that also included tumours diagnosed by radiology. However, the precision of the estimates was substantially reduced, as indicated by the wide CIs (data not shown).

\section{DISCUSSION}

In this prospective follow-up of a large population-based cohort, we found that BMI among women, but not in men, was positively associated with the risk of meningioma. Thus, obese women had a $68 \%$ increased risk of meningioma compared with normal weight women (BMI of $20-24.9 \mathrm{~kg} \mathrm{~m}^{-2}$ ). Further, results were suggestive of an inverse association between BMI and the risk of schwannoma. There was no evidence for any association between BMI and height and the risk of glioma in this study.

It is a major strength of this study that $87.4 \%$ of the eligible adult population participated, suggesting that the participants are fairly representative for the underlying population of Nord-
Trøndelag county in Norway. In relation to many key indicators, this county is also quite representative for Norway as a whole (Holmen et al, 2003). Another strength of the study is that the anthropometric factors were measured as part of the physical examination, and not self-reported.

Incidence data in the Cancer Registry of Norway is of high quality, including completeness and validity (Larsen et al, 2009). On the basis of these data, we could assess risk among subgroups of CNS tumours. Accordingly, $95 \%$ of the gliomas, $58 \%$ of the meningiomas and $46 \%$ of the schwannomas were diagnosed by histological examination, whereas the diagnoses of the remaining tumours were based on radiological examination. Although the sensitivity and specificity of radiological diagnosis is high for meningiomas and schwannomas, the method has limited value for further tumour classification and grading (Bydder et al, 1985; Elster et al, 1989; Wilms et al, 1989; Schorner et al, 1990). Another weakness of this study was that data on incident cancers other than CNS tumours were not available. These individuals could therefore not be censored but remained in the analysis.

Changes in BMI during follow-up may be a concern and could not be assessed in this study. Also, meningiomas and schwannomas are slow growing tumours that may not be detected early in the course, but could nonetheless have influenced body mass before being diagnosed. To reduce this possible bias we excluded incident tumours during the first 5 years of follow-up, but the estimated effects related to schwannoma and meningioma risk remained stable. Yet another concern may be that our findings could reflect the increased surveillance of obese individuals due to increased co-morbidity that may lead to more frequent radiological exams in this group. To minimise this potential bias, we restricted the analysis to tumours diagnosed by histology, but found no substantial difference in the estimates of effect. This did not change the HRs for schwannoma or meningioma, but reduced the power of the analysis.

A limitation of this study is that BMI was the only measure for adiposity, as data on waist and hip circumference were not available in the HUNT 1 study. An association between waist circumference and meningioma risk could have strengthened the finding of an association with adiposity as measured by BMI. 
The positive association of BMI with meningioma risk among women has also been observed in four other cohort studies (Jhawar et al, 2003; Benson et al, 2008; Johnson et al, 2011; Michaud et al, 2011), but the results between studies vary both in magnitude and precision. In the Million Women study, obese women (BMI $\geqslant 30$ ) were at $40 \%$ higher risk compared to women with BMI $<25$ (HR 1.40, 95\% CI: $1.08-1.87$ ), and in the EPIC study, there was a similar risk increase in obese women (HR 1.48, 95\% CI: 0.98-2.23). In the Nurses' Health Study, a BMI $\geqslant 25$ was associated with $61 \%$ higher risk of meningioma compared to women with BMI $<25$ (HR 1.61, 95\% CI: 0.96-2.70). In the Iowa Women's Health Study, however, the association of BMI was substantially stronger, though with some variation according to the initial questionnaire in 1986 (HR 2.14, 95\% CI: 1.36-2.36) and follow-up questionnaire in 1992 (HR 1.91, 95\% CI: 1.21-3.01) for women in the BMI category $30-34.9$ compared with the reference $\left(18.5-24.9 \mathrm{~kg} \mathrm{~m}^{-2}\right)$. Among these cohorts, only the EPIC study has reported results for men, suggesting a positive, but not statistically significant association with BMI. We could not find any association between meningioma risk and BMI in males, but the results must be interpreted with caution owing to small numbers.

Body mass index is closely correlated with body fat mass, and adipose tissue is highly endocrine active (Spiegelman et al, 1992). Higher body fat volume has been associated with higher levels of estrogens, androgens and insulin-like growth factor (Hankinson et al, 1995; Cleary and Grossmann, 2009). Case reports have suggested that meningiomas may progress during pregnancy and after long-term therapy with progesterone agonists (Saitoh et al, 1989; Wan et al, 1990; Ismail et al, 1998; Gruber et al, 2004). In vitro studies have shown proliferation of meningioma cells that were exposed to progesterone and oestrogen (Speirs et al, 1997) and the incidence of meningiomas is about twice as high in women than men (Kreftregisteret, 2011; CBTRUS, 2012). These findings suggest that endogenous hormones may be involved in the development or progression of meningiomas, where higher levels of estrogens and growth factors in obese women may enhance tumour growth. Unfortunately, a detailed analysis of hormonerelated factors (i.e., reproductive history, hormone replacement therapy and menopausal status) could not be assessed in this population.

We could not confirm the previously reported positive association between height and meningioma risk. However, previous results were inconsistent, and the precision of the estimated effects of height has been low, suggesting that the reported associations may be likely due to chance (Helseth and Tretli, 1989; Benson et al, 2008; Johnson et al, 2011; Michaud et al, 2011). Height has also been positively associated with glioma risk in some, but not in other studies (Benson et al, 2008; Moore et al, 2009; Michaud et al, 2011). In our data, there was no evidence for any association of height with the risk of glioma.

To our knowledge, no previous study has assessed anthropometry and schwannoma risk. It is a rare disease, but in spite of small numbers, our results were suggestive of a negative association between BMI and the risk of schwannoma. We also found smoking to be negatively associated with the risk of schwannoma. In a population-based case-control study current smoking was also inversely associated with schwannoma risk (Schoemaker et al, 2007). However, data on BMI was not included. A recent population-based cohort study by Benson et al (2010) confirmed the inverse association with current smoking status. As smoking is negatively associated with BMI, the inverse association of BMI with risk of schwannoma may have been confounded by smoking. However, the inverse association persisted after controlling for smoking, and the trend was even stronger than in the age- and sexadjusted model. Smoking has been shown to decrease the risk of oestrogen-dependant tumours like endometrial and postmenopausal breast cancer. The finding that parous women also have a higher risk of schwannoma (Schoemaker et al, 2007) and the fact that schwannomas may express hormone receptors (Siglock et al, 1990; Filipo et al, 1995; Carroll et al, 1997) may strengthen the hypothesis that endogenous hormones have a role in schwannoma development. However, our results of a negative association with body mass is not completely in line with this hypothesis. Smoking may also delay the diagnosis schwannoma as smoking is associated with impaired hearing (Cruickshanks et al, 1998). This may therefore camouflage the hearing loss associated with schwannoma development in smokers, leading to detection bias. Finally, results in this tumour subgroup are based on small numbers, and we cannot completely rule out that findings may be due to chance.

In most epidemiological studies, primary CNS neoplasms have been considered as one entity. However, these tumours have different embryological origins and their carcinogenesis may therefore differ. In line with this, our results show different associations of anthropometric measures with different tumour subgroups. Further studies should therefore distinguish between subgroups of tumours and avoid using CNS tumours as one entity.

Our results confirm that there is a positive association of BMI with meningioma risk in women, and our results also suggest an inverse association between BMI and the risk of schwannoma.

\section{ACKNOWLEDGEMENTS}

The Nord-Trøndelag Health Study (The HUNT Study) is a collaboration between HUNT Research Centre (Faculty of Medicine, Norwegian University of Science and Technology NTNU), Nord-Trøndelag County Council, Central Norway Health Authority and the Norwegian Institute of Public Health.

\section{REFERENCES}

Benson VS, Green J, Pirie K, Beral V (2010) Cigarette smoking and risk of acoustic neuromas and pituitary tumours in the Million Women Study. Br J Cancer 102(11): 1654-1656.

Benson VS, Pirie K, Green J, Casabonne D, Beral V (2008) Lifestyle factors and primary glioma and meningioma tumours in the Million Women Study cohort. Br J Cancer 99(1): 185-190.

Bondy M, Wiencke J, Wrensch M, Kyritsis AP (1994) Genetics of primary brain tumors: a review. J Neurooncol 18(1): 69-81.

Bydder GM, Kingsley DP, Brown J, Niendorf HP, Young IR (1985) MR imaging of meningiomas including studies with and without gadoliniumDTPA. J Comput Assist Tomogr 9(4): 690-697.

Calle EE, Rodriguez C, Walker-Thurmond K, Thun MJ (2003) Overweight, obesity and mortality from cancer in a prospectively studied cohort of US adults. N Engl J Med 348(17): 1625-1638.

Carroll RS, Zhang JP, Black PM (1997) Hormone receptors in vestibular schwannomas. Acta Neurochir 139(3): 188-192discussion 193.

CBTRUS (2012) CBTRUS Statistical Report: Primary Brain and Central Nervous System Tumors Diagnosed in the United States in 2004-2008 (Revised 23 March 2012) http://www.cbtrus.org/reports/reports.html.

Chakrabarti I, Cockburn M, Cozen W, Wang YP, Preston-Martin S (2005) A population-based description of glioblastoma multiforme in Los Angeles County, 1974-1999. Cancer 104(12): 2798-2806.

Cleary MP, Grossmann ME (2009) Minireview: obesity and breast cancer: the estrogen connection. Endocrinology 150(6): 2537-2542.

Cruickshanks KJ, Klein R, Klein BE, Wiley TL, Nondahl DM, Tweed TS (1998) Cigarette smoking and hearing loss: the epidemiology of hearing loss study. JAMA 279(21): 1715-1719.

Edlinger M, Strohmaier S, Jonsson H, Bjorge T, Manjer J, Borena WT, Haggstrom C, Engeland A, Tretli S, Concin H, Nagel G, Selmer R, Johansen D, Stocks T, Hallmans G, Stattin P, Ulmer H (2012) Blood pressure and other metabolic syndrome factors and risk of brain tumour in the large population-based Me-Can cohort study. J Hypertens 30(2): 290-296. 
Elster AD, Challa VR, Gilbert TH, Richardson DN, Contento JC (1989) Meningiomas: MR and histopathologic features. Radiology 170(3 Pt 1): 857-862.

Filipo R, Petrangeli E, Monini S, Ortolani F, Gulino A, Barbara M, Frati L (1995) Expression of steroid receptors in acoustic neuroma. Clin Otolaryngol Allied Sci 20(5): 413-417.

Fisher JL, Schwartzbaum JA, Wrensch M, Wiemels JL (2007) Epidemiology of brain tumors. Neurol Clin 25(4): 867-890vii.

Gruber T, Dare AO, Balos LL, Lele S, Fenstermaker RA (2004) Multiple meningiomas arising during long-term therapy with the progesterone agonist megestrol acetate. Case report. J Neurosurg 100(2): 328-331.

Hankinson SE, Willett WC, Manson JE, Hunter DJ, Colditz GA, Stampfer MJ, Longcope C, Speizer FE (1995) Alcohol, height and adiposity in relation to estrogen and prolactin levels in postmenopausal women. J Natl Cancer Inst 87(17): 1297-1302.

Helseth A, Tretli S (1989) Pre-morbid height and weight as risk factors for development of central nervous system neoplasms. Neuroepidemiology 8(6): 277-282.

Holmen J, Forsen L, Hjort PF, Midthjell K, Waaler HT, Bjorndal A (1991) Detecting hypertension: screening versus case finding in Norway. $B M J$ 302(6770): 219-222.

Holmen J, Midthjell K, Krüger O, Langhammer A, Lingaas Holmen T, Bratberg G, Vatten L, Lund-Larsen P (2003) The Nord-Trøndelag Health Study 1995-97 (HUNT 2): objectives, contents, methods and participation. Norsk Epidemiol 13(1): 19-32.

Inskip PD, Linet MS, Heineman EF (1995) Etiology of brain tumors in adults. Epidemiol Rev 17(2): 382-414.

Ismail K, Coakham HB, Walters FJ (1998) Intracranial meningioma with progesterone positive receptors presenting in late pregnancy. Eur J Anaesthesiol 15(1): 106-109.

Jhawar BS, Fuchs CS, Colditz GA, Stampfer MJ (2003) Sex steroid hormone exposures and risk for meningioma. J Neurosurg 99(5): 848-853.

Johnson DR, Olson JE, Vierkant RA, Hammack JE, Wang AH, Folsom AR, Virnig BA, Cerhan JR (2011) Risk factors for meningioma in postmenopausal women: results from the Iowa Women's Health Study. Neuro Oncol 13(9): 1011-1019.

Kreftregisteret (2011) Cancer Registry of Norway. Cancer in Norway 2009. Cancer incidence, mortality, survival and prevalence in Norway..

Larsen IK, Smastuen M, Johannesen TB, Langmark F, Parkin DM, Bray F, Moller B (2009) Data quality at the Cancer Registry of Norway: an overview of comparability, completeness, validity and timeliness. Eur J Cancer 45(7): 1218-1231.

Michaud DS, Bove G, Gallo V, Schlehofer B, Tjonneland A, Olsen A, Overvad K, Dahm CC, Teucher B, Boeing H, Steffen A, Trichopoulou A, Bamia C, Kyrozis A, Sacerdote C, Agnoli C, Palli D, Tumino R, Mattiello A, Bueno-de-Mesquita HB, Peeters PH, May AM, Barricarte A, Chirlaque MD, Dorronsoro M, Jose Sanchez M, Rodriguez L, Duell EJ, Hallmans G, Melin BS, Manjer J, Borgquist S, Khaw KT, Wareham N, Allen NE, Travis RC, Romieu I, Vineis P, Riboli E (2011) Anthropometric measures, physical activity, and risk of glioma and meningioma in a large prospective cohort study. Cancer Prev Res 4(9): 1385-1392.

Moore SC, Rajaraman P, Dubrow R, Darefsky AS, Koebnick C, Hollenbeck A, Schatzkin A, Leitzmann MF (2009) Height, body mass index, and physical activity in relation to glioma risk. Cancer Res 69(21): 8349-8355.

Oh SW, Yoon YS, Shin SA (2005) Effects of excess weight on cancer incidences depending on cancer sites and histologic findings among men:
Korea National Health Insurance Corporation Study. J Clin Oncol 23(21): 4742-4754.

Parr CL, Batty GD, Lam TH, Barzi F, Fang X, Ho SC, Jee SH, AnsaryMoghaddam A, Jamrozik K, Ueshima H, Woodward M, Huxley RR (2010) Body-mass index and cancer mortality in the Asia-Pacific Cohort Studies Collaboration: pooled analyses of 424,519 participants. Lancet Oncol 11(8): 741-752.

Preston-Martin S (1996) Epidemiology of primary CNS neoplasms. Neurol Clin 14(2): 273-290.

Renehan AG, Roberts DL, Dive C (2008) Obesity and cancer: pathophysiological and biological mechanisms. Arch Physiol Biochem 114(1): 71-83.

Ries LAGEM, Kosary CL, Hankey BF, Miller BA, Clegg L, Mariotto A, Fay MP, Feuer EJ, Edwards BK (eds)Accessed on 06 April (2011) SEER Cancer Statistics Review, 1975-2001. National Cancer Institute: Bethesda, MD, USA, seer.cancer.gov/csr/1975_2001).

Ronning PA, Helseth E, Meling TR, Johannesen TB (2012) A population-based study on the effect of temozolomide in the treatment of glioblastoma multiforme. Neuro Oncol 14(9): 1178-1184.

Saitoh Y, Oku Y, Izumoto S, Go J (1989) Rapid growth of a meningioma during pregnancy: relationship with estrogen and progesterone receptors. Neurol Med Chir 29(5): 440-443.

Schoemaker MJ, Swerdlow AJ, Auvinen A, Christensen HC, Feychting M, Johansen C, Klaeboe L, Lonn S, Salminen T, Tynes T (2007) Medical history, cigarette smoking and risk of acoustic neuroma: an international case-control study. Int J Cancer 120(1): 103-110.

Schorner W, Schubeus P, Henkes H, Rottacker C, Hamm B, Felix R (1990) Intracranial meningiomas. Comparison of plain and contrast-enhanced examinations in CT and MRI. Neuroradiology 32(1): 12-18.

Siglock TJ, Rosenblatt SS, Finck F, House WF, Hitselberger WE (1990) Sex hormone receptors in acoustic neuromas. Am J Otol 11(4): 237-239.

Speirs V, Boyle-Walsh E, Fraser WD (1997) Constitutive co-expression of estrogen and progesterone receptor mRNA in human meningiomas by RT-PCR and response of in vitro cell cultures to steroid hormones. Int J Cancer 72(5): 714-719.

Spiegelman D, Israel RG, Bouchard C, Willett WC (1992) Absolute fat mass, percent body fat, and body-fat distribution: which is the real determinant of blood pressure and serum glucose? Am J Clin Nutr 55(6): 1033-1044.

Tulinius H, Sigfusson N, Sigvaldason H, Bjarnadottir K, Tryggvadottir L (1997) Risk factors for malignant diseases: a cohort study on a population of 22,946 Icelanders. Cancer Epidemiol Biomarkers Prev 6(11): 863-873.

Umansky F, Shoshan Y, Rosenthal G, Fraifeld S, Spektor S (2008) Radiationinduced meningioma. Neurosurg Focus 24(5): E7.

Wan WL, Geller JL, Feldon SE, Sadun AA (1990) Visual loss caused by rapidly progressive intracranial meningiomas during pregnancy. Ophthalmology 97(1): 18-21.

Wilms G, Decrop E, Plets C, Demaerel P, Marchal G, Van Hecke P, Baert AL (1989) Magnetic resonance imaging in acoustic neurinoma. Comparison with CT. J Belge Radiol 72(3): 151-158.

This work is published under the standard license to publish agreement. After 12 months the work will become freely available and the license terms will switch to a Creative Commons AttributionNonCommercial-Share Alike 3.0 Unported License. 